thie-Score. Nicht apathische Patienten zeigten in den Off-Phasen mit etwa 0,6\% eine ähnliche Belohnungsempfindlichkeit wie gesunde Kontrollpersonen, in den On-Phasen lagen sie mit rund $1,3 \%$ jedoch deutlich darüber. Parkinson-Patienten ohne Apathie offenbaren unter der dopaminergen Medikation in OnPhasen also ein deutlich aktiveres Belohnungssystem als Gesunde. Anders sah es bei apathischen Patienten aus: Bei ihnen fanden die Forscher in den Off-Phasen überhaupt keine Aktivität $(0 \%)$, und in den On-Phasen lag sie mit rund $0,3 \%$ noch deutlich unter den Werten der Gesunden. Die Belohnungsempfindlichkeit war insgesamt umso geringer, je höhere Apathiewerte die Neurologen feststellten.

Ganz anders sah es bei den depressiven Parkinson-Kranken aus: Sie reagierten in den Tests nicht anders als Parkinson-Pa- tienten ohne Depressionen und Apathie. Eine schlechte Belohnungsempfindlichkeit, wie sie sich über die Pupillenreaktion ablesen lässt, ist nach Ansicht der Forscher um Husain daher ein recht spezifisches Zeichen für eine Apathie. Für interessant halten die Wissenschaftler den Zusammenhang mit der dopaminergen Medikation: Sie verbessert auch bei den apathischen Patienten die Motivation. Möglicherweise lasse sich die Apathie durch eine optimierte dopaminerge Therapie deutlich lindern. Ärzte sollten bei der Medikation also nicht nur die motorischen Symptome im Blick haben.

Thomas Müller, Springer Medizin

Oral Session "cognitive neurology/neuropsychology" (02107).

Muhammed K et al. Insensitivity to reward characterizes apathy but not

depression in Parkinson's. 2. EAN-Kongress, Kopenhagen, 28. - 31.5.2016

\title{
Experten fordern: Europa sollte sich besser auf Zika vorbereiten
}

\begin{abstract}
Eine großflächige Ausbreitung von Zika-Viren in Europa ist zwar wenig wahrscheinlich, doch eingeschleppte Fälle und eine sexuelle Übertragung könnten auch hier zum Problem werden.
\end{abstract}

Das Zika-Virus breitet sich immer stärker in tropischen und subtropischen Regionen aus, inzwischen berichten 60 Länder von einer anhaltenden Übertragung der Infektion durch Mücken. „Die Zika-Epidemie hat längst globale Dimensionen erreicht", erläuterte Professor Raad Shakir, Präsident des Weltneurologenverbands WFN. „Und Europa wird davon nicht verschont werden", sagte der Neurologe auf einer EAN-Pressekonferenz. Zehn Länder, darunter auch Deutschland, melden Transfers von Mensch zu Mensch - hier wird vor allem eine sexuelle Übertragung eingeschleppter Viren vermutet. So kann das Virus mehrere Wochen, vermutlich sogar Monate, im Sperma persistieren. Insgesamt sind in Deutschland rund ein Dutzend Erkrankungen registriert worden, eine Meldepflicht besteht allerdings erst seit dem 1. Mai.

\section{Auch für Erwachsene problematisch}

Shakir warnte davor, die Erkrankung zu verharmlosen. „Viele Menschen glauben noch immer, Zika sei nur ein Problem für Ungeborene. Das Virus kann jedoch auch bei Erwachsenen schwere neurologische Komplikationen wie Guillain-BarréSyndrom (GBS), Myelitis oder Meningoenzephalitis auslösen.“ Der Neurologe wies darauf hin, dass eine Zika-Virus-Infektion das Risiko für eine GBS um etwa das 60 -fache erhöht. In 13 Ländern wurden mittlerweile erhöhte GBS-Inzidenzen oder GBSFälle nach Zika-Erkrankungen festgestellt. Europa habe zwar gute Karten, die Herausforderung zu bewältigen, erläuterte Professor John England, Vorsitzender der Zika-Arbeitsgruppe der WFN. So könnten Zika-Patienten mit ZNS-Komplikationen von der guten neurologische Versorgung profitieren. Allerdings bestehe eine, wenn auch eher geringe Gefahr, dass sich das Virus in der Mückenpopulation in Südeuropa ausbreitet. Es gebe einige Populationen der Gelbfiebermücke Aedes aegyptii auf Madeira oder am Schwarzen Meer. Dieses Insekt gilt als Hauptvek- tor für Zika. Allerdings könnte sich das Virus auch die Asiatische Tigermücke (Aedes albopictus) als Transportvehikel aneignen - sie ist weit häufiger in Südeuropa zu finden. Die meisten Zika-Fälle dürften in den kommenden Monaten allerdings von Reisenden nach Europa eingeschleppt werden. England verwies auf die WHO-Warnung, wonach Schwangere Gebiete mit ZikaVerbreitung unbedingt meiden sollten. Dazu zählt auch das diesjährige Olympialand Brasilien. Der Experte sagte, dass rund jede dritte an Zika erkrankte Schwangere ein Kind mit neurologischen Schäden zur Welt bringe.

Männer sollten nach der Rückkehr aus Zika-Gebieten mindestens vier Wochen auf Sex verzichten oder Kondome benutzen, um eine Übertragung zu vermeiden. Mit Blick auf die olympischen Spiele in Brasilien verwies England auf die WHO-Empfehlungen, wonach Athleten und Besucher der Spiele sich gut vor Mückenstichen schützen sollten, indem sie Repellenzien benutzen, adäquate Kleidung tragen und klimatisierte Unterkünfte bevorzugen.

\section{Gefahr für Afrika}

Weshalb das schon vor 80 Jahren entdeckte Zika-Virus plötzlich neurologische Komplikationen verursacht, ist noch weitgehend unklar. „Es ist wohl durch eine Mutation neurotrop geworden und kann dadurch ins Gehirn der Feten gelangen." Das Virus befalle und töte dort vor allem neuronale Vorläuferzellen. Bekannte antivirale Mittel könnten nichts dagegen ausrichten, erläuterte Shakir. Ein Rätsel ist ebenfalls, weshalb manche Menschen an Zika erkranken, wohingegen die Infektion bei rund $80 \%$ asymptomatisch verläuft. Shakir gab zu bedenken, dass viele der Betroffenen unter schlechten hygienischen Bedingungen leben, sodass multiple Infekte leicht möglich sind. Vielleicht bahnen andere Erreger den Weg für eine Zika-Infektion. Shakir befürchtet daher erhebliche Probleme, sollte der neurotrope Zika-Stamm von Süd- und Mittelamerika nach Afrika gelangen. Ohne ausreichende medizinische Versorgung sei es dort für viele Familien eine erhebliche Belastung, schwer behinderte Kinder zu versorgen.

Thomas Müller, Springer Medizin

Pressekonferenz, 2. EAN-Kongress, Kopenhagen, 28. - 31.5.2016 